\title{
Vibration Reduction in Aerospace Bracket through Structural Design
}

\author{
Murali Mohan Raju.T ${ }^{1}$ Anjaiah Madarapu ${ }^{2}$ M.Manzoor Husain ${ }^{3}$ \\ ${ }^{1.2}$ Associate Professor, Mechanical Engineering Department, School of Engineering \& Technology, Guru \\ Nanak Institutions Technical Campus, Hyderabad, A.P., INDIA. \\ ${ }^{3}$ Professor, Mechanical Engineering Department, JNT University, Hyderabad, A.P., INDIA
}

\begin{abstract}
Brackets will be used as an interface for mounting subsystems in aerospace vehicles. Dynamic loads like vibration originated from the external sources like aerodynamic pressure will first act on the aerospace vehicle. This will transmit to the subsystem through the interface bracket. Subsystems are supposed to deliver the intended functions safely without getting influenced by vibration. If the influence of vibration on subsystems is high there are three ways to reduce the effect of vibration. The structural design of the bracket is fine tuned such a way that the amplification in vibration between the bracket and the subsystem is to be minimized. For doing so first the vibration response for the present configuration is estimated using Finite Element Method (FEM). From the response plot frequencies which will contribute more to the response are understood. Frequency and mode shape in combination gives a overall idea about structural modification. Vibration control of one of the bracket of an aerospace vehicle is taken up in this project. The above said approach is adopted for reducing the vibration in the bracket.
\end{abstract}

\section{Introduction}

Bracket is nothing but a rectangular plate of size $275 \times 225 \times 10 \mathrm{~mm}$. Bracket is made of aluminium and its weight is about $1.7 \mathrm{Kg}$. Bracket is having four holes of diameter $5 \mathrm{~mm}$ with which it will be fitted to the aerospace vehicle. Subsystem which is mounted on the plate is of size $200 \mathrm{~mm} \times 150 \mathrm{~mm} \times 50 \mathrm{~mm}$. Weight of the subsystem is considered to be $3 \mathrm{Kg}$. Bracket with subsystem mounted on it is shown in Fig. 1.

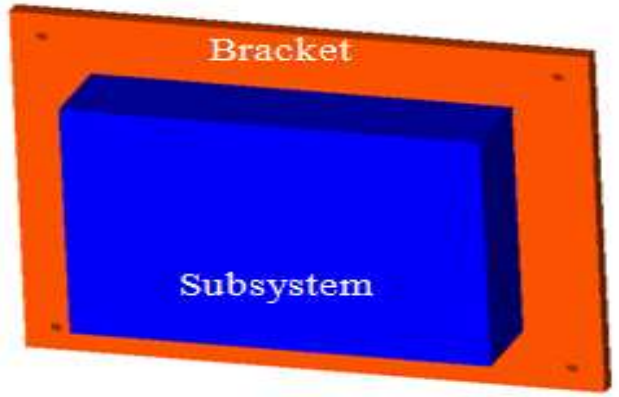

Fig. 1. Bracket with mounted subsystem

\section{Dynamic Load}

Random vibration will be often experienced by the aerospace vehicle [1]. Hence random vibration is considered as dynamic load. The input random vibration curve is shown in Fig. 2.

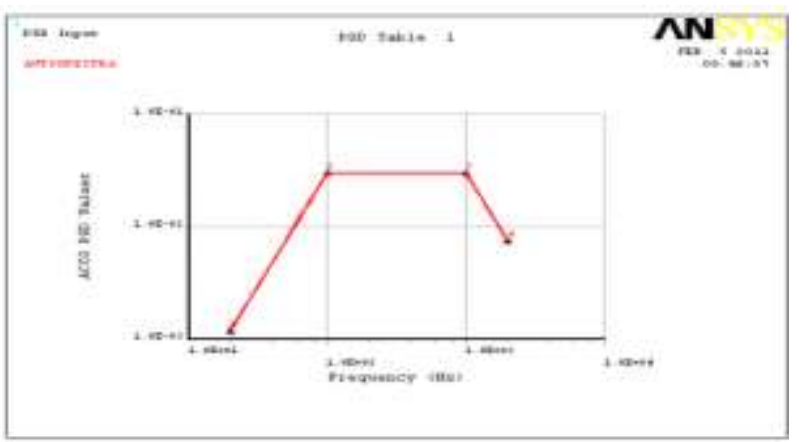

Fig. 2. Dynamic load in random vibration 
Random vibration will be specified in terms of the area under the curve and the corresponding dynamic input value here is $6.5 \mathrm{~g}$.

\section{Finite Element Modeling}

Random vibration analysis of the bracket with subsystem is carried out using FEM in ANSYS software

Geometry of the bracket is built up in SOLIDWORKS software. Geometry model is converted into FE model by dividing the bracket using 4 nodded linear quadrilateral shell elements (SHELL 63) in ANSYS software. A 8 nodded solid brick element (SOLID 45) is defined to consider the subsystem. For carrying out structural analysis material properties of aluminum (Material for bracket) [3] are considered.

- $\quad$ All the nodes on edges of the four holes are restrained.

- Dynamic load shown in Fig. 2. Is applied.

FE model is shown in Fig. 3.

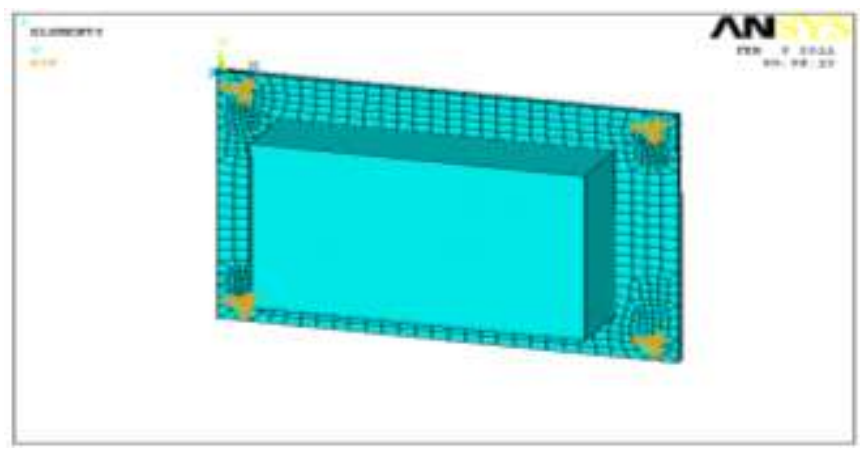

Fig. 3. FE model of bracket with subsystem

\section{Modal Analysis}

Random vibration analysis of the bracket with subsystem is carried out using FEM in ANSYS software. The objective of carrying out modal analysis is to find out the natural frequencies of the bracket within the frequency band of input. Any practical structure (Continuous body) possesses infinite natural frequencies. But for this the natural frequencies, which are present in the frequency range of input, are only of interest. Hence it is essential to find out the natural frequencies through modal analysis before carrying out random vibration response analysis. Block Lanczos algorithm of ANSYS software is used for extracting the frequencies. From the analysis first frequency of the bracket is found to be $572 \mathrm{~Hz}$. Mode shape corresponding to this frequency is shown in Fig. 4.

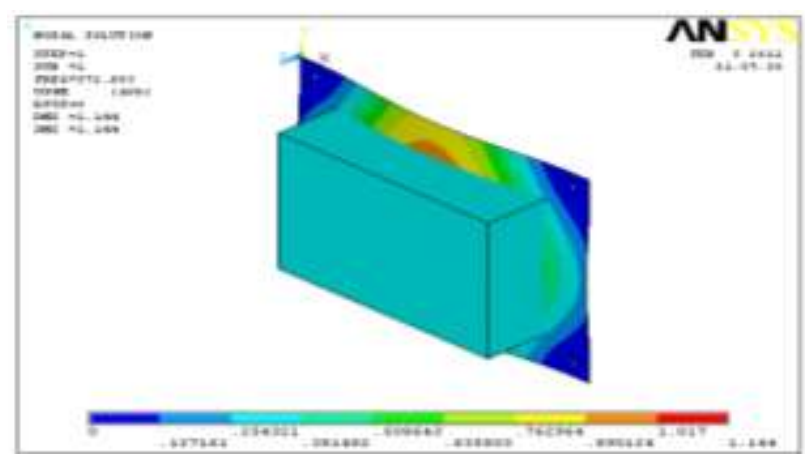

Fig. 4. Mode shape of the bracket

\section{Random Vibration Response Analysis}

In ANSYS software the type of the analysis is set as spectrum (which will be used to perform random vibration response analysis) as shown below. Input curve shown in Fig. 2. is applied to the bracket model. Response obtained near the mounting location of the subsystem and input is shown in Fig. 5. 


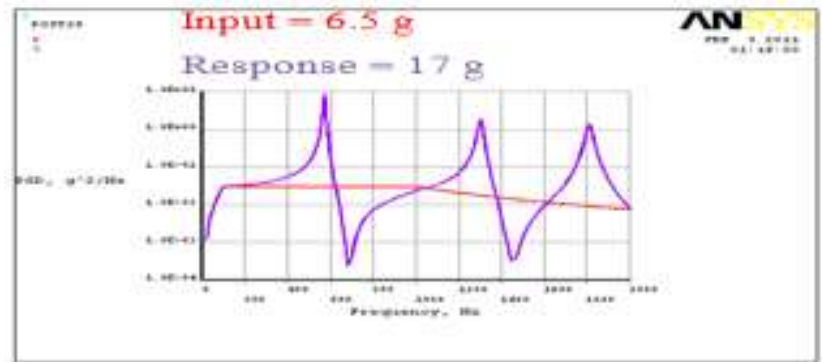

Fig. 5. Response of the bracket

\section{Vibration Reduction By Structural Modification}

Vibration control by structural modification is adopted to reduce the high vibration response on bracket $(17.8 \mathrm{~g})$. Structural modification can be achieved by altering

- Stiffness

- Mass

- Damping

Among these it is well known fact that by increasing the damping vibration response gets reduces. But as increasing damping and there by getting benefit of reducing the vibration response is ruled out as it is practically difficult. Rest two methods to reduce vibration response are assumed to be altering

- Stiffness

- Mass

\section{Structural Modification By Increasing The Stiffness}

Stiffness of the bracket is increased by adding a rib of size 3 x $15 \mathrm{~mm}$ as shown in Fig. 6 .

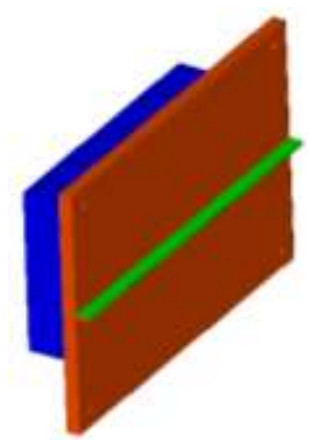

Fig. 6. Bracket with rib

Vibration response analysis is carried out for this configuration and is shown in Fig. 7.

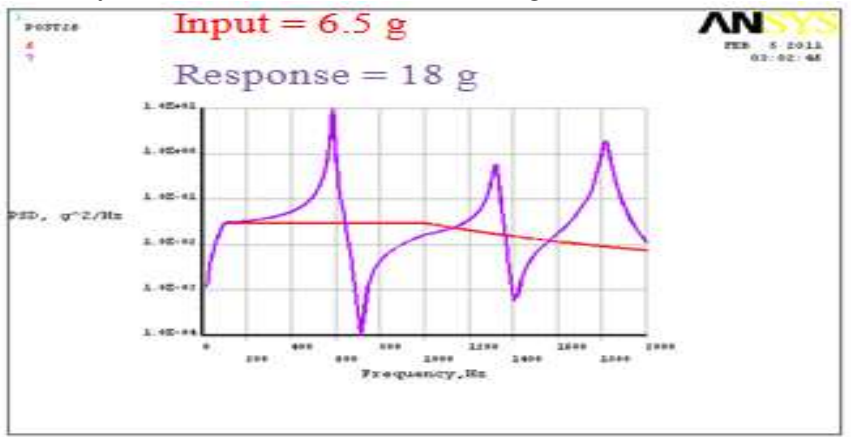

Fig. 7. Response of the bracket

- By increasing the stiffness vibration response got increased from $17 \mathrm{~g}$ to $18 \mathrm{~g}$.

- It indicates that vibration response varies directly proportional to stiffness.

\section{Structural Modification By Increasing The Mass}

Mass of the bracket is increased by increasing its thickness from $10 \mathrm{~mm}$ to $15 \mathrm{~mm}$. Vibration response analysis is carried out for this configuration and is shown in Fig. 8. 


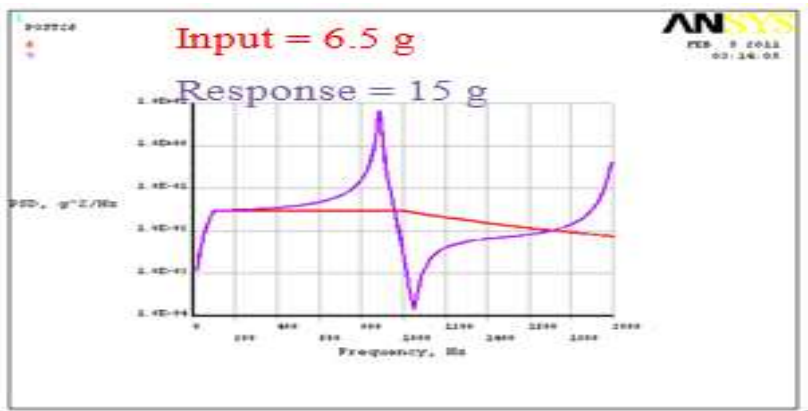

Fig. 8. Response of the bracket

- By increasing the mass vibration response got reduced from $17 \mathrm{~g}$ to $15 \mathrm{~g}$.

- It indicates that vibration response varies inversely with that of mass.

\section{Structural Modification - 1}

It is evident from above sections that either reducing the stiffness or increasing the mass will be beneficial. But increasing mass alone is not preferred option for aerospace applications. Hence crux of the whole exercise gives an interesting message that while decreasing the thickness as the mass reduces, mass has to be compensated for reducing stiffness so that overall mass remains unaltered. Keeping this in view the thickness of the bracket is reduced from $10 \mathrm{~mm}$ to $5 \mathrm{~m}$ only in the area beneath the subsystem. Thickness of rest of the portion is increased from $10 \mathrm{~mm}$ to $19.43 \mathrm{~mm}$ so that overall mass of the bracket is unaltered. Vibration response analysis is carried out for this configuration and is shown in Fig. 9.

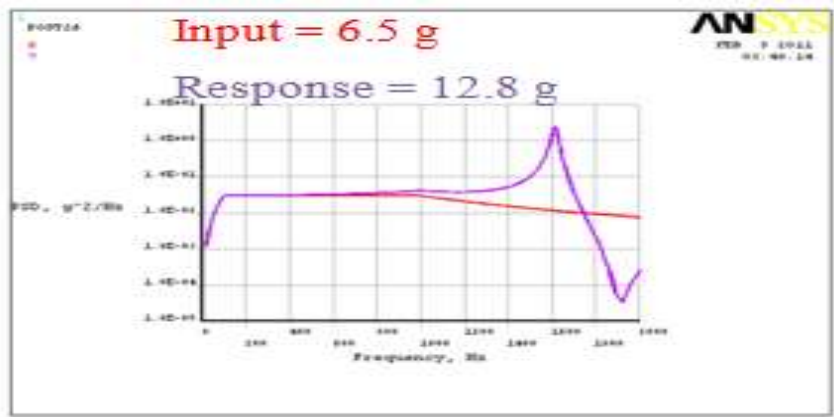

Fig. 9. Response of the bracket

- With the optimum structural modification the vibration response got reduced from $17 \mathrm{~g}$ to $12.8 \mathrm{~g}$

\section{Optimum Structural Modification-2 (Final Recommended)}

It is decided to modify the structure further to reduce the response some more. Before proceeding for modification the mode shape corresponding to the frequency shown in Fig. 9 is examined and shown in Fig. 10.

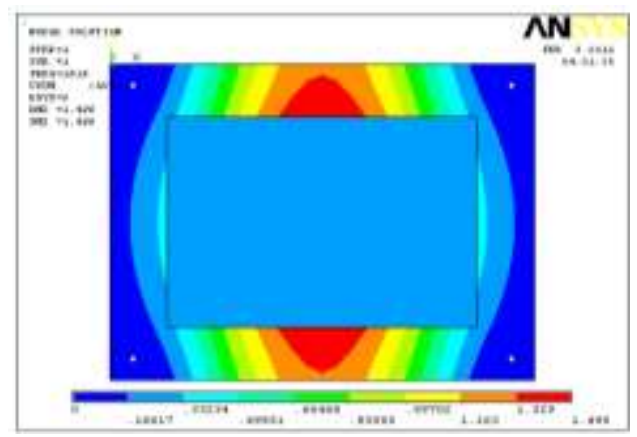

Fig. 10. Mode shape of bracket

From the above mode shape it is visible that the zone (Marked in red colour) has less stiffness and the zone (Marked in blue colour) has more stiffness. Thickness in more stiffness zone is reduced from $19.43 \mathrm{~mm}$ to $10 \mathrm{~mm}$ to reduce the overall stiffness which is beneficial. Further the thickness in less stiffness zone is increased from $19.43 \mathrm{~mm}$ to $24.35 \mathrm{~mm}$ to increase the mass influence. But however while making these changes, mass is maintained as unaltered. Vibration response analysis is carried out for this configuration and is shown in Fig. 11. 


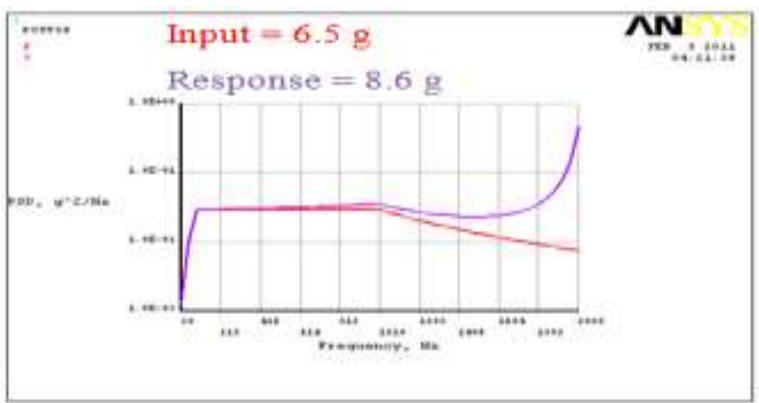

Fig. 11. Response of the bracket

With the final recommended configuration the response got reduced to a greater extent from $17 \mathrm{~g}$ to $6.5 \mathrm{~g}$

\section{Results and Discussion}

The results obtained for various configurations are compared in Table 1.

\begin{tabular}{|l|l|l|}
\hline $\begin{array}{c}\text { Sl. } \\
\text { No. }\end{array}$ & \multicolumn{1}{|c|}{ Configuration } & \multicolumn{1}{|c|}{$\begin{array}{c}\text { Vibration } \\
\text { response }\end{array}$} \\
\hline 1. & Prior & $17 \mathrm{~g}$ \\
\hline 2. & With increasing stiffness & $18 \mathrm{~g}$ \\
\hline 3. & With increasing mass & $15 \mathrm{~g}$ \\
\hline 4. & Optimum configuration -1 & $12.8 \mathrm{~g}$ \\
\hline 5. & Optimum configuration -2 (Final) & $8.6 \mathrm{~g}$ \\
\hline
\end{tabular}

Table 1. Comparison of results

- Vibration response varies in proportion with that of stiffness.

- Whereas it varies inversely with that of mass.

- Optimum modification of stiffness while maintaining same mass results in tremendous reduction in vibration response.

\section{Conclusion}

Tremendous reduction in vibration response experienced by a bracket of aerospace vehicle is achieved by optimum tuning of stiffness and mass. The outcome of this work established an unique fact that while maintaining the mass same, altering the stiffness results in reduction of vibration response. It also conveys a message that vibration response varies directly with stiffness and varies inversely with mass.

\section{References}

[1] Stephen H. Crandall, "Random vibration", Technology press, Wiley, New York, 1958.

[2] ANSYS user manual.

[3] S. L. Hoyt, Metals and alloys data book, Reinhold, New York, 1943. 